\title{
¿Existe futuro en los medios de comunicación públicos? Análisis del giro editorial de Diario El Telégrafo entre 2017 y 2018
}

\section{¿Is there a future for the public media in Ecuador? Analysis of the changes in the editorial line of "Diario El Telégrafo" between 2017-2018}

Cristian Bravo Gallardo

Recepción: 31-05-2020

Aceptación: 29-07-2020

\section{Resumen}

La presente investigación busca reflexionar acerca del papel de los medios de comunicación públicos en el Ecuador. Ello a través de un seguimiento de la línea editorial de Diario El Telégrafo durante 2017 y 2018, a fin de identificar los principales giros en su línea editorial. La investigación plantea también la generación de nuevos espacios de debate en materia de medios de comunicación, sociedad y democracia.

Palabras clave: democracia, medios públicos, medios de comunicación, Ecuador, sociedad

\section{Abstract}

This article tries to ponder the part of the public media in Ecuador through the follow up of the editorial line of Diario El Telégrafo between 2017 and 2018. The purpose of it is the identification of the main changes in the editorial policy of the mentioned newspaper. In addition, the investigation proposes the creation of new debate areas among the media, communication, society and democracy.

Key words: democracy, public media, media, communication, Ecuador, society 


\section{Introducción}

$\mathrm{E}$

n el mundo contemporáneo, la comunicación desempeña un rol determinante, llegando a modificar las formas de vida, de socialización y representación. Grupos y sectores sociales buscan ser visibilizados en los grandes medios de comunicación. Ello ha generado la necesidad de profundizar su democratización, a fin de establecer nuevas formas de representar realidades diversas. Es por esto que el posicionamiento de nuevos medios de comunicación aparece como fundamental, al ser una necesidad vital para sectores de la población que han sido marginados.

La evolución de la sociedad del conocimiento está conectada a las discusiones sobre el derecho a la libertad de expresión y al acceso universal a la información en el mundo. Los debates en torno a libertad de prensa, medios de comunicación, nuevas tecnologías, políticas públicas, gobierno abierto; son algunos de los temas que se han puesto sobre el tapete.

El estudio de los medios públicos desde una perspectiva de análisis de desempeño constituye una iniciativa necesaria; ello en vista de que en la actualidad aún persisten confusiones conceptuales sobre la razón de ser de estos medios. No se ha realizado, en ese sentido, un seguimiento de los criterios que deben regir y que dan sentido a los medios públicos, así como un análisis objetivo sobre el comportamiento de los medios gubernamentales.

La importancia de hacer un seguimiento y análisis sobre los medios de comunicación públicos está en realizar una valoración de su accionar y desempeño, como veeduría de su trabajo y aporte tanto al periodismo como a la propia ciudadanía. Brindar una mirada clara sobre la situación de los medios públicos, que muestre su deber ser, demostrar lo que son en la actualidad y lo que deben ser en el futuro, aparece como una obligación y una responsabilidad. Conceptos como transparencia, rendición de cuentas, calidad en la producción de contenidos, manejo de recursos, desempeñan un papel fundamental al hablar de medios públicos. La presente investigación busca ser un aporte para el análisis en materia de medios de comunicación públicos, cumpliendo las exigencias de la sociedad latinoamericana a fin de contar con medios que estén al servicio de todos. 
Para realizar un análisis profundo en este ámbito, el presente estudio hace un repaso sobre un sinnúmero de definiciones respecto a la comunicación, la libertad de expresión, democracia, así como las interacciones entre medios de comunicación y poder político. En tal sentido, se plantea dar respuestas a algunas interrogantes tales como: ¿Cuál es el rol de los medios públicos? y ¿Cuáles han sido los principales giros realizados por los medios públicos? Para ello se tomará como elemento de análisis a Diario El Telégrafo.

En las últimas décadas, los medios de comunicación se han convertido en agentes para la gobernabilidad, así como en actores importantes que participan en la sociedad. Sin medios no existe una adecuada gobernabilidad; las acciones y estrategias de comunicación política empleadas en países de la región así lo demuestran. Por ello, es de capital interés analizar las acciones y la gestión desarrollada por los medios públicos en el Ecuador, tomando en cuenta las tensiones generadas durante los últimos años en el país en torno a varios ámbitos político y económico. A través de una investigación exploratoria y apoyada en una metodología cualitativa, se desarrollará un análisis, en torno al papel de los medios de comunicación públicos en el Ecuador, a fin de profundizar en el estudio de la comunicación como disciplina y de la democracia como sistema político.

Un adecuado desempeño de los medios públicos permitirá la generación de nuevos espacios de diálogo entre las instituciones y la sociedad civil, mejorando el desempeño de los gobiernos y por ende el sistema democrático en la región; en tal sentido este trabajo plantea nuevos debates en torno a la función que deben cumplir estos actores para una mayor democratización de la sociedad. La presente investigación busca también despertar el interés en el ámbito académico en torno al rol que deben tener los medios de comunicación en una sociedad.

\section{Metodología}

La metodología de investigación a desarrollar en el presente trabajo, se basará en una combinación de aspectos cuantitativos, a través de un monitoreo y búsqueda de editoriales, con respecto a la gestión gubernamental entre 2017 y 2018; y aspectos cualitativos en donde se analizarán los contenidos empleados en los titulares y editoriales, que permitan observar el tratamiento 
de la información por parte de este medio e identificar su posición con respecto al régimen de turno.

\section{Fundamentación teórica}

Son varios los enfoques que se han debatido en torno a los medios públicos en América Latina. En el Ecuador se promovió a Diario El Telégrafo como medio público cuando en 2008 pasó a manos del Estado. Sin embargo, ello se lo hizo sin la generación del debate respectivo en torno a la constitución de medios públicos en nuestro país.

El análisis de un hecho de relevancia para el país como son los medios de comunicación, en este caso los medios públicos, implica una revisión sobre la historia de los medios de comunicación en el Ecuador, el desarrollo que ha tenido la prensa pública en América Latina y en el Ecuador. Para ello, hay que mencionar autores a fin de profundizar y entender las diferentes teorías sobre los medios de comunicación.

Harold Lasswell (1948), sociólogo estadounidense dedicado al estudio de la influencia de los medios de comunicación y de información de masas en el proceso de creación de la opinión pública y autor del modelo "¿Quién dice qué, a quién, por qué canal y con qué efecto?" establece cinco funciones de los medios de comunicación en términos de las necesidades de la sociedad y de los individuos: Informar, interpretar, transmitir la herencia cultural, entretener y movilizar. El emisor según Lasswell, nace deseando controlar los medios, en consecuencia la audiencia y por consiguiente los efectos.

Bernard Berelson, sociólogo estadounidense e investigador de políticas de población y experto de las teorías de comunicación social que analizan los efectos de los medios de comunicación masiva en el público, plantea por su parte que gracias a la prensa el lector queda inserto en la élite informadora del grupo, distinguiéndose de ella. La escuela funcionalista a cual pertenece Berelson señala que la sociedad tiene un conjunto de necesidades y un conjunto de instituciones para satisfacer esas necesidades.

El filósofo, profesor y teórico canadiense Marshall McLuhan, con marcada influencia en la cultura contemporánea a través de estudios sobre los efectos de los medios de comunicación en los procesos sociales, el arte y la 
literatura, fue uno de los pioneros en la esfera de la información y la comunicación y de la influencia de los nuevos medios. "El medio es el mensaje", frase desarrollada por McLuhan, actualmente es un lema para las ciencias de la comunicación contemporáneas. Todos los medios ejercen una influencia compulsiva en el hombre y en la sociedad según McLuhan y la manera de percibir la realidad se relaciona directamente con la estructura y la forma de la información. Además, cada medio está relacionado con una parte de la psiquis humana.

Por otro lado, teóricos de la comunicación y estudiosos de los medios públicos en la región permiten establecer un concepto adecuado de un medio público así como el funcionamiento en nuestra sociedad. Omar Rincón, periodista y académico colombiano, considera que los medios son públicos en la medida en que se inscriben en los proyectos colectivos de la sociedad, en la medida que permitan aumentar la pluralidad de interpretaciones de la realidad. Rincón propone la "creatividad social" como fuente y soporte de los medios públicos considerados por él como contadores de historias entretenidas y experimentales, porque responden a necesidades de acceso, expresión y saber del ciudadano.

Jesús Martín Barbero plantea que los medios públicos deben ofrecer diversidad cultural y promover una información independiente, plural e incluyente de las diferentes situaciones regionales.

Por otro lado, está la teoría de la agenda setting McCombs y Shaw (1972), la cual destaca la capacidad que tienen los medios de comunicación para medir la importancia de la información que se va a difundir.

Al hablar de agenda setting, la teoría presenta tres tipos de agendas que se relacionan en el proceso comunicativo, definiendo a cada una de ellas como principales elementos del proceso de la agenda setting. La primera agenda es la agenda de los medios de comunicación, la cual aparece como una variable que permite la generación de contenidos que ocuparán las portadas de los medios. En segundo lugar está la agenda pública, la cual destaca la investigación centrada en la importancia que da el público a determinados aspectos noticiosos durante un período de tiempo. Finalmente está la agenda política o institucional, que mide el tipo de acciones que adoptan los 
gobiernos, parlamentos y las diferentes instituciones sociales que más tarde formarán parte de los debates en la sociedad. Esta agenda es la encargada de generar temas nuevos que influyen la agenda de los medios y la del público. Esta teoría se basa en la importancia que le da el diario público a los temas publicados en portada, y primeras secciones, además de los actores protagonistas en las noticias, la colocación del espacio publicitario y la cantidad de artículos editoriales que presenta.

La teoría del encuadre, Gaye Tuchman (1978) señala que los medios definen varias pautas o marcos con los que pretenden favorecer una determinada interpretación de los hechos sobre los que informan. El uso de esta teoría responde a las prácticas profesionales y teorías del objetivismo informativo. El periodista es un analista de la realidad y su finalidad es dar al ciudadano elementos que le permitan una comprensión de los temas, mientras que él se sitúa en el terreno de la neutralidad, considerada como un paso más hacia la utopía objetivista. La teoría del encuadre fundamenta el enfoque que le dan los diarios públicos a las noticias presentadas, la influencia que puede generar en el público con la forma en cómo se redacta una noticia.

\section{Medios y Democracia}

Mediante la generación y transmisión de información, los medios de comunicación se han convertido en la actualidad en actores determinantes. Desde el pensamiento liberal, los medios son entendidos como un elemento clave para la materialización de libertades fundamentales como la libertad de pensamiento y libertad de expresión; estos son vistos también como herramientas fundamentales en la búsqueda de un pluralismo informativo, participación ciudadana así como de transparencia de la política, la cual está sujeta al examen de la sociedad.

Benjamín Constant considera que la más importante de las libertades sociales es la libertad de prensa. "Sólo a través de ella se logra difundir opiniones diversas y, mediante su confrontación, acercarse a la verdad. Se trata del único medio de publicidad y, por tanto, la garantía última de los ciudadanos: todas las limitaciones al poder se vuelven una quimera sin la luz de los medios" (Jardin, 1989). 
La libertad de prensa históricamente ha sido entendida como un camino y una lucha permanente para evitar el abuso del poder político; los medios han sido un canal que permite la circulación de información relevante para la comunidad. La lucha por una prensa autónoma se ha enfocado en no permitir la intromisión del Estado, así como la generación de espacios en donde las opiniones circulen libremente.

En las últimas décadas, el interés de los gobiernos por la censura ha sido permanente; el tema mediático plantea en la actualidad nuevas amenazas de diverso origen: crecimiento de la industria mediática, intereses comerciales, el nacimiento de nuevos medios con particularidades técnicas, que han permitido su desarrollo y preeminencia desde mediados del siglo XX (Keane, 1991). En varios países de la región, el peligro para un libre acceso de los ciudadanos a la información, surge a través de un proceso de concentración en la propiedad de medios de comunicación, así como de la aparición de agencias transnacionales que deciden unilateralmente los hechos a informarse y la manera de hacerlo (Muro, 2006). De esta manera, a la preocupación por la intromisión estatal en el escenario mediático, se suma la amenaza por la acumulación y concentración de medios de comunicación, la cual está lejos de ser neutral y se reduce a la satisfacción de intereses específicos.

La democracia no tiene que ver únicamente con las formas y procedimientos de un gobierno, sino que se trata de un sistema de derechos que está entre los pilares esenciales de un proceso de gobierno democrático (Dahl, 1999). Como proceso histórico, esta debe ser entendida como un asunto en permanente cambio y transformación. Ello nos permite afirmar que no se puede hablar de una democracia completa. En ese sentido, la relevancia de la comunicación aparece como en elemento fundamental para el fortalecimiento de la misma; ello hace que los medios de comunicación mantengan un papel importante en el fortalecimiento de los procesos democratizadores.

Sin embargo, se debe entender a los medios de comunicación como recursos de poder que pueden ser o no, utilizados democráticamente. El carácter comercial de los medios de comunicación en ocasiones ha reducido la esfera pública mediática al ámbito del espectáculo, en lugar de ser un escenario de confluencia de informaciones, argumentos, razonamientos sobre la 
sociedad, sus problemas y soluciones. Es por ello que dentro del ámbito de la comunicación, su papel resulta determinante para propiciar los procesos de transición eventual y consolidación democrática.

\section{Los medios de comunicación en el Ecuador}

A lo largo de su historia, Ecuador ha sido un país con una baja tradición en medios públicos, siendo la empresa privada la principal impulsora de medios en el país. Hasta finales del siglo XX, el Estado Central mantenía 3 estaciones de radio marginales en AM: Radio Nacional del Ecuador, Radio Casa de la Cultura y Radio Vigía de la Policía Nacional. Este escenario cambió una vez que el Estado se hizo cargo de 2 importantes medios de comunicación, que pertenecían a banqueros quebrados y cuya propiedad fue cedida como parte de pago a los clientes.

Por el desinterés del Estado de controlar grandes medios de comunicación, estas 2 empresas fueron entregadas a administraciones independientes (en el caso de Diario El Telégrafo) o vendidas a empresas privadas (como la estación televisiva Sí TV, hoy Canal UNO). Sin embargo, durante la administración del presidente Rafael Correa se dio un giro sustancial en esta tendencia, dándose así una mayor presencia del Estado en el sector mediático, a través de varias estrategias concretas:

a. El fortalecimiento institucional de los medios de comunicación estatales existentes y la creación de nuevas entidades informativas. El Estado permitió un reposicionamiento de Diario El Telégrafo; la creación de Ecuador TV, como primer canal de televisión pública, el fortalecimiento de Radio Nacional del Ecuador (RPE) y la expansión en la cobertura de Radio Casa de la Cultura.

b. El control de 12 medios de comunicación vinculados al Grupo Isaías (ex dueño del cerrado Filanbanco), a través de una acción coactiva respaldada en la Ley de la Agencia de Garantía de Depósitos, que protege la devolución de su dinero a los ciudadanos al cerrarse una entidad financiera. Entre las entidades confiscadas estuvieron Gama TV y TC Televisión. También pasó al Estado el Grupo TV Cable (operadora de televisión pagada), así como varias radios y editoriales. 
El Gobierno designó nuevas autoridades en los medios incautados, encargados de supervisar la información de los noticieros de esas estaciones, ahora estatales. Ello generó la reacción de organismos como la Sociedad Interamericana de Prensa (SIP), que a través de su presidente, Gonzalo Marroquín señaló que: “... lo que no se sostiene bajo ningún punto de vista es que esa acción de las empresas haya sido complementada con someter la política editorial, nombrando un director periodístico gubernamental (...). Esa medida no hace otra cosa que disfrazar de licitud, una política de censura".

La acción coactiva ocurrió 2 meses y medio antes de que el Gobierno someta a votación su proyecto de nueva Constitución; ello fue interpretado por analistas políticos como una estrategia mediática del régimen para impulsar un voto positivo a su propuesta de aprobar una nueva Carta Magna. Los editoriales de los principales periódicos señalaron que resultaba cuestionable que el Estado maneje medios de comunicación incautados durante un proceso electoral.

El Estado levantó en menos de 2 años un nuevo grupo mediático con el control de 17 medios de comunicación: 5 de manera directa y 12 por encargo. Esto es 4 canales de televisión abierta VHF y UHF; 2 estaciones de televisión pagada, 1 proveedora de televisión internacional, 1 diario nacional, 4 revistas y 5 radios.

A pesar de que el presidente de aquel entonces señaló que esas empresas informativas no serían manejadas a largo plazo por el Estado, autoridades gubernamentales defendieron el derecho del Gobierno a comprar los medios de comunicación incautados, acción que no se ha concretó.

La irrupción del Estado en los medios de comunicación generó un enfrentamiento permanente entre el Gobierno y los medios de comunicación privados. Desde el Ejecutivo, el Presidente de la República cuestionó la credibilidad de la prensa independiente. Así también, la relación entre la banca y los medios de comunicación fue suspendida durante la administración de Rafael Correa, a través de la implementación de dos acciones fundamentales:

Tanto el referéndum de Consulta Popular de 2008, sobre la prohibición de que instituciones del sistema financiero privado, empresas de comunicación privadas nacionales (sus directores y principales accionistas), ten- 
gan participación accionaria fuera del ámbito financiero o comunicacional, así como la modificación de la Ley de Contratación Pública (Decreto No. 1793), que prohíbe a las empresas mantener capitales fuera del país, afectó la estabilidad de varios medios de comunicación privados, algunos de los cuales dejaron de publicarse como fue el caso de Revista Vanguardia, medio que detuvo sus publicaciones a mediados de 2013. Estas acciones modificaron la presencia y accionar de los medios de comunicación y abrieron un escenario de nuevas confrontaciones matizadas con la salida de periodistas, y algunas figuras visibles en los medios privados.

Los cambios en la estructura empresarial y mediática del país crearon un nuevo panorama en donde los medios de comunicación pasaron al banquillo de los acusados, algo que nunca había ocurrido en el Ecuador. El discurso crítico de Rafael Correa estuvo cargado de descalificaciones respecto de los medios privados, quienes respondieron duramente a las críticas realizadas, declarándose perseguidos del poder político, lo cual negó cualquier posibilidad de diálogo.

En ese escenario, los medios públicos cobraron mayor protagonismo en el país; en 2007, se creó Ecuador TV (ECTV), canal que abrió el camino para la creación de otros medios de diverso formato. La creación y administración de nuevos medios públicos coincidió con la corriente política de corte progresista, implementada en varios países de la región (Venezuela, Argentina y Bolivia), conocida también como "Socialismo del siglo XXI" (Souza, 2010). 


\section{Cuadro 1}

\begin{tabular}{|c|c|}
\hline \multicolumn{2}{|c|}{$\begin{array}{c}\text { Listado de medios incautados por el Estado Ecuatoriano y } \\
\text { medios públicos }\end{array}$} \\
\hline Medios incautados & Nuevos medios públicos \\
El Telégrafo & Ecuador TV ECTV \\
Gama TV & Radio Pública \\
Canal UNO & Agencia de Noticias Andes \\
TC Televisión & Rotativo Interino el Ciudadano \\
Cable Visión & Periódico Popular PP EL VER- \\
Radio Súper K 800 & \\
Radio Carrusel & \\
Radio La Prensa & \\
Multicom & \\
Cable Noticias CN3 & \\
Cabre Deportes CD7 & \\
Radio El Telégrafo & \\
Revista La Onda & \\
Revista El Agro & \\
Revista El Valle & \\
Revista Sanborondón & \\
\hline
\end{tabular}

Fuente: Elaboración propia

\section{Características y posicionamiento de los medios públicos en el Ecuador}

Es importante profundizar en el concepto, esencia y características de lo que es, un medio de comunicación. Para ello, hay que señalar que un medio de comunicación público debe estar al servicio de la ciudadanía y los intereses colectivos de un país. La necesidad de insistir sobre las características de los medios públicos está dada en que en la actualidad muchos gobiernos continúan usando los medios de comunicación "públicos", como medios oficialistas o medios de gobierno. 
Para Martín Barbero, los medios públicos "deben ofrecer reconocimiento y expresión de la diversidad cultural; representación de la diversidad ideológico-política; promover una información independiente, plural e incluyente de las diferentes situaciones regionales" (CIESPAL, 2009) .

En América Latina no se han desarrollado políticas de comunicación claras, pensadas en perspectiva de Estado sino en función de los gobiernos de turno (Rincón, 2010). En el caso ecuatoriano, las directrices en relación al rumbo y objetivos de la comunicación mediática desarrollada en el seno de los medios públicos, la decide la Secretaría Nacional de Comunicación (SECOM), con una inclinación de naturaleza gubernamental. Esta gestión del Estado está respaldada por el artículo 384, de la Constitución de la República del Ecuador, que establece la facultad del Estado para formular la política pública de comunicación.

En lo referente a los medios públicos, falta el desarrollo de una mayor planificación, manteniendo dinámicas de poder, con acercamientos hacia la generación de contenidos educativos y a la producción nacional. Así también, en el país se mantiene una fuerte cultura del espectáculo vinculada con los círculos de poder de turno, lo cual ha generado un enfrentamiento permanente cuyos protagonistas principales son el Gobierno Central y los medios privados de comunicación.

Agrupaciones como la Asociación de Editores de Periódicos (AEDEP), impulsaron campañas pidiendo mayor respeto al trabajo de la prensa, proceso que tuvo un eco internacional. La organización Fundamedios manifestó que en el Ecuador se dio un paulatino deterioro de la libertad de prensa (Fundamedios, 2009), lo cual también fue reconocido en su momento por la Sociedad Interamericana de Prensa (SIP). Las tres agrupaciones fueron descalificadas por el presidente de ese entonces Rafael Correa Delgado.

La disputa por la agenda en el Ecuador llevó a un conflicto entre medios públicos y privados, lo cual generó una gran exposición del presidente y su círculo político; ello permitió la configuración de un "estado comunicador" (Rincón, 2010) que desarrolló una fuerte política de inversión publicitaria, la cual fue incrementándose mes a mes. De esa forma, el Estado se convirtió en el principal anunciante del país. Por su parte, los medios privados se 
vieron inmersos en un discurso de violencia que fue debilitando la calidad de la información y la relación con el ciudadano común.

El discurso periodístico de los medios públicos del Ecuador, mantuvo su dependencia de las fuentes oficiales (Querejeta, 2009), lo cual alteró su misión. Un ejemplo de ello fue la cobertura mediática de la revuelta policial el 30 de septiembre de 2010 en donde se dio un control de la información por parte del gobierno. Es por ello que la independencia de los medios públicos, sigue siendo un tema que genera debate en el país. Así también se pudo ver en el Ecuador un alineamiento de los medios privados en contra de la gestión gubernamental en varios los frentes (Abad, 2009).

Frente a ello, se puede señalar que el propósito fundamental de los medios de comunicación debe ser proporcionar al ciudadano la información necesaria para que este tenga la capacidad de interpretar la realidad y tomar decisiones adecuadas ante determinados acontecimientos. En ese sentido los medios públicos tienen la obligación de ofrecer una programación acorde a los intereses de los diferentes grupos ciudadanos.

En el Ecuador se ha provocado un distanciamiento entre los medios públicos y los medios privados, configurándose así una tendencia marcada por la defensa de intereses particulares tanto desde el Estado como desde el sector privado en cuanto al desarrollo de información. Esta particularidad está determinada por estructuras sociales en la que los medios de comunicación se adhieren (Mastrini, 2014). Durante varios años se consolidó en la opinión pública la lógica del "extremista intolerante que miente y busca desestabilizar al gobierno", frente al bando a los "tolerantes, que dicen y que consolidan la verdad.

La permanente campaña política, en la que varios gobiernos de la región han transitado, hizo que se confunda el verdadero rol del medio público frente al rol de un medio gubernamental. Los medios públicos eran los encargados de divulgar actos y realizaciones gubernamentales por lo que se convirtieron en un instrumento ideológico, en la medida en que hacía públicas posiciones y aclaraciones que llegaban desde el Ejecutivo sobre a asuntos de interés social (De Moraes, 2011). De esta manera, los medios públicos fueron utilizados como una propiedad estatal cuya única finalidad era la asistencia 
gubernamental. Al no contar con ese apoyo, estos medios se convirtieron en el foco de atención de empresas extranjeras para promocionar sus productos.

La fuerza de los medios públicos fue importante en su momento en América Latina y el control al que estaban sometidos los medios privados por parte del Estado también. Con el transcurso de los años, ese poder se invirtió, los medios públicos no lograron competir con sus similares privados. El carácter educativo, cultural y hasta elitista no tuvo la capacidad de competir con un medio comercial.

Con la llegada de Rafael Correa al poder, el Estado desarrolló un proyecto de medios públicos el cual incluyó la refundación de varios medios como Radio Pública del Ecuador, inaugurada en agosto de 2008, la creación de un canal de televisión abierto (Ecuador TV), inaugurado en abril de 2008. En marzo de 2008 entró en circulación Diario El Telégrafo como diario público (Macaroff, 2010). Apareció, también, el periódico gubernamental El Ciudadano y se creó la Agencia Pública de Noticias del Ecuador y Sudamérica (ANDES). Finalmente, en septiembre de 2010 entró en circulación el diario público popular "PP, El Verdadero", en versión tabloide, el cual pasó a editarse e imprimirse en las instalaciones de El Telégrafo (UNESCO, 2011).

A pesar de que la Ley de Comunicación identifica a los medios de comunicación en públicos, privados y comunitarios, cada uno con un porcentaje similar del espectro radioeléctrico, el discurso presidencial fue permanente e incisivo en el fortalecimiento de los medios públicos; ello formó parte de una estrategia mediática del gobierno anterior que permitió poner en marcha una tipificación de los medios de comunicación.

En el contexto latinoamericano, con los desaparecidos Hugo Chávez y Néstor Kirchner, a los que se sumaron Cristina Fernández, Evo Morales, Lula da Silva y Rafael Correa, se legitimó un discurso de confrontación con los medios de comunicación privados. Al mismo tiempo, se permitió el fortalecimiento de los medios públicos, gubernamentales, así como el nacimiento de los medios comunitarios.

El posicionamiento de un actor antagónico identificado en la prensa privada, sus propietarios y periodistas, permitió que los ciudadanos demanden calidad en los contenidos que éstos entregan, demanda que se fortaleció 
por la regulación a la que fueron sometidos. En ese escenario, la credibilidad de los medios públicos que ajustaron su programación a la excesiva promoción estatal, sin reparo a la crítica y con un síntoma parcializado, perdieron credibilidad. Por su parte, los medios privados actuaron de manera similar al desplegar información en defensa de intereses determinados, mostrándose como actores políticos y económicos con una férrea oposición al régimen. Follari (2009) destaca que en países como Argentina, Venezuela, Bolivia y Ecuador los grandes medios de comunicación pasaron de ser los portavoces de la oposición al consolidarse ellos mismo como actores políticos opositores. Acción política que se ejerció bajo el antifaz de la una supuesta objetividad apolítica (Macaroff, 2010).

\section{El Telégrafo: Principales giros}

Los medios públicos, que existen en las democracias maduras, tienen estructuras institucionales que bloquean, de la mayor manera posible, al gobierno sobre su manejo editorial. Un ejemplo de ello es la BBC de Londres, manejada por un consejo integrado por personas independientes del gobierno. Décadas atrás, aquel medio se resistió a los intentos de Margaret Thatcher a que tome una posición pro británica durante la guerra de Las Malvinas. Thatcher murió convencida de que la BBC había estado del lado del "enemigo" durante la guerra y nunca perdonó a ese medio que no se haya referido a los soldados británicos como "nuestros soldados" sino en tercera persona como los "soldados británicos".

En el mundo entero son pocos los casos de diarios que son propiedad del Estado o del partido en el gobierno. Éstos se limitan a países donde hay dictaduras como Cuba o democracias precarias como Kenya. De hecho, en ninguna democracia europea hay diarios públicos, aunque sí hay radio y televisión pública por el simple hecho de que el espectro radioeléctrico es propiedad del Estado.

En el Ecuador, Diario El Telégrafo no ha logrado estructurar un paraguas jurídico ni institucional que garantice que cualquier tipo de gobierno pueda influir en su política editorial, tal como se lo hizo en la administración de Rafael Correa. Ello ha dificultado que este medio impreso pueda ser consi- 
derado como un medio público real. El hecho de que el director de ese medio sea nombrado por el presidente de turno, lo convierte en un cargo político. Por más méritos y buenas intenciones que tengan sus autoridades, siempre llegará el día en que sus decisiones terminen siendo influenciadas por el poder. De esta manera, no habrá la independencia suficiente y es posible que el medio termine siendo un portavoz más del gobierno.

Un informe realizado por el ex gerente de la Empresa de los Medios Públicos, Andrés Michelena, confirmó meses atrás lo comentado desde varios sectores del país; que los medios en manos del Gobierno fueron manejados al antojo de las decisiones políticas y conveniencias económicas.

¿Por qué lado salvar a los medios públicos, si ni siquiera mostraron ética en su información? Lo invirtieron todo, ni siquiera mostraron otra verdad, a la misma verdad la invirtieron y se creyeron su mentira pues había dinero de por medio. En el caso de Diario El Telégrafo, este se manejó en pérdida, esto es de cada 10 ejemplares, seis iban a la basura. Falta aún que oficialmente se indague al diario, solo los informes ya existentes de Contraloría muestran sus malos manejos, ello sumado a los contratos que el diario hizo con ministerios, se pueden encontrar varias sorpresas adicionales.

“El Telégrafo compró el Diario El Tiempo de Cuenca. Y aquí viene el hecho que sorprendió al mismo Gerente de los medios públicos. Por una imprenta "vetusta" se pagó un millón y medio de dólares. (Hablar de millones de dólares en la revolución ciudadana es como hablar de centavos...) Adicionalmente se paga ocho mil dólares mensuales a los exdueños del diario El Tiempo, por las instalaciones del medio. Es decir, el diario no fue vendido, solo la imprenta y su nombre. Ahora los periodistas serán reubicados en otro sitio, pues esas instalaciones son privadas. “ ¡Vaya negocio el realizado entre el Estado y la familia Toral! Si se pretendiera vender el diario, no hay posibilidad, no hay nada que vender... ¿Una imprenta? Según el propio informe, está valorada quizá en 80.000 dólares” (Minga, 2017).

En las tablas que se muestran a continuación, constan los temas y contenidos desarrollados en los editoriales durante los años 2017 y 2018 en 
los que se abordan temas políticos. En ellos se puede ver el giro realizado en la línea editorial por parte de Diario El Telégrafo como medio público. Entre enero y mayo de 2017 se observa una posición de firme defensa al Gobierno de turno, en donde incluso se ataca fuertemente y de manera reiterativa a los opositores al régimen de ese entonces. Los meses en los que se evidencia una mayor radicalidad en los contendidos son marzo y abril de 2017. Los temas durante ese tiempo están enfocados en el ámbito político y en un contexto electoral y es ahí donde se visualiza una posición de marcado respaldo al régimen de turno y a sus principales figuras, en especial al candidato que en ese entonces representaba el Gobierno, desconociendo el verdadero papel que tienen los medios públicos. A partir de junio del 2017 y durante el 2018, ya con una nueva administración en el país, se observa que si bien la línea o política editorial de Diario El Telégrafo no establece cuestionamientos del nuevo Gobierno, la diversidad de contenidos a parte del tema político es evidente. Ello evidencia que si bien se han dado pasos dados importantes para un mejor funcionamiento de los medios públicos en el país, aún se debe trabajar para su fortalecimiento, a fin de que el gobierno o mandatario de turno no asuma a este tipo de medios como medios gubernamentales u oficialistas.

\section{Cuadro 2}

Editoriales Diario El Telégrafo año 2017

\begin{tabular}{|c|c|c|c|}
\hline No. & EDITORIAL & FECHA & LINK \\
\hline 1 & $\begin{array}{l}\text { Las previsiones para la economía } \\
\text { son optimistas }\end{array}$ & $30-12-17$ & $\begin{array}{l}\frac{\mathrm{https}: / / \text { www.eltelegrafo.com. }}{\mathrm{ec} / \text { noticias/editoriales/1/las- }} \\
\text { previsiones-para-la-economia- } \\
\text { son-optimistas }\end{array}$ \\
\hline 2 & $\begin{array}{l}\text { La economía debe manejarse en } \\
\text { un clima de confianza }\end{array}$ & $22-11-17$ & $\frac{\frac{\mathrm{https}: / / \text { www.eltelegrafo.com. }}{\text { ec/noticias/editoriales/1/la- }}}{\frac{\text { economia-debe-manejarse-en- }}{\text { un-clima-de-confianza }}}$ \\
\hline 3 & $\begin{array}{c}\text { Apoyo vital del Gobierno al Festi- } \\
\text { val de las Artes de Loja }\end{array}$ & $20-11-17$ & $\begin{array}{l}\text { https://www.eltelegrafo.com. } \\
\text { ec/noticias/editoriales/1/ } \\
\text { apoyo-vital-del-gobierno-al- } \\
\text { festival-de-las-artes-de-loja }\end{array}$ \\
\hline
\end{tabular}




\begin{tabular}{|c|c|c|c|}
\hline 4 & $\begin{array}{c}\text { Esta casa se ordena de otra forma } \\
\text { a partir de hoy }\end{array}$ & $14-11-17$ & $\begin{array}{l}\text { https://www.eltelegrafo.com. } \\
\text { ec/noticias/editoriales/1/esta- } \\
\text { casa-editorial-se-ordena-de- } \\
\text { otra-forma-a-partir-de-hoy }\end{array}$ \\
\hline 5 & $\begin{array}{l}\text { Medios públicos deben ser un } \\
\text { espacio de la sociedad }\end{array}$ & $01-11-17$ & $\begin{array}{l}\text { https://www.eltelegrafo.com. } \\
\text { ec/noticias/editoriales/1/ } \\
\text { medios-publicos-deben-ser- } \\
\underline{\text { un-espacio-de-la-sociedad }}\end{array}$ \\
\hline 6 & $\begin{array}{l}\text { El tradicional "paquetazo" fue } \\
\text { descartado de plano }\end{array}$ & $13-10-17$ & $\begin{array}{l}\text { https://www.eltelegrafo.com. } \\
\text { ec/noticias/editoriales/1/ } \\
\text { el-tradicional-paquetazo-fue- } \\
\text { descartado-de-plano }\end{array}$ \\
\hline 7 & $\begin{array}{l}\text { Todo el dinero de la corrupción } \\
\text { debe ser devuelto al estado }\end{array}$ & $10-10-17$ & $\begin{array}{l}\text { https://www.eltelegrafo.com. } \\
\text { ec/noticias/editoriales/1/todo- } \\
\text { el-dinero-de-la-corrupcion- } \\
\text { debe-ser-devuelto-al-estado }\end{array}$ \\
\hline 8 & $\begin{array}{l}\text { Medidas austeras para reducir el } \\
\text { derroche de gastos }\end{array}$ & $11-09-17$ & $\begin{array}{l}\frac{\text { https://www.eltelegrafo.com. }}{\text { ec/noticias/editoriales/1/ }} \\
\text { medidas-austeras-para- } \\
\text { reducir-el-derroche-de-gastos }\end{array}$ \\
\hline 9 & $\begin{array}{l}\text { Jorge Glas se distancia de Lenin } \\
\text { Moreno, ¿Qué busca? }\end{array}$ & 03-08-17 & $\begin{array}{l}\frac{\text { https://www.eltelegrafo.com. }}{\text { ec/noticias/editoriales/1/jorge- }} \\
\frac{\text { glas-se-distancia-de-lenin- }}{\text { moreno-que-busca }}\end{array}$ \\
\hline 10 & $\begin{array}{l}\text { Transparentar las cifras: el primer } \\
\text { paso para enfrentar la crisis econó- } \\
\text { mica del país }\end{array}$ & $30-07-17$ & $\begin{array}{l}\text { https://www.eltelegrafo.com. } \\
\text { ec/noticias/editoriales/1/ } \\
\text { transparentar-las-cifras-el- } \\
\text { primer-paso-para-enfrentar-la- } \\
\text { crisis-economica-del-pais }\end{array}$ \\
\hline 11 & $\begin{array}{l}\text { El diálogo como una herramienta } \\
\text { para construir país }\end{array}$ & $27-07-17$ & $\begin{array}{l}\frac{\text { https://www.eltelegrafo.com. }}{\text { ec/noticias/editoriales/1/ }} \\
\frac{\text { el-dialogo-como-una- }}{\text { herramienta-para-construir- }} \\
\text { pais }\end{array}$ \\
\hline 12 & $\begin{array}{l}\text { Medios públicos incluyentes, sin } \\
\text { vetos de ninguna índole }\end{array}$ & 21-07-17 & $\begin{array}{l}\text { https://www.eltelegrafo.com. } \\
\text { ec/noticias/editoriales/1/ } \\
\text { medios-publicos-incluyentes- } \\
\text { sin-vetos-de-ninguna-indole }\end{array}$ \\
\hline 13 & $\begin{array}{l}\text { La independencia de funciones } \\
\text { contribuye a la transparencia }\end{array}$ & $20-07-17$ & $\begin{array}{l}\text { https://www.eltelegrafo.com. } \\
\text { ec/noticias/editoriales/1/la- } \\
\text { independencia-de-funciones- } \\
\text { contribuye-a-la-transparencia }\end{array}$ \\
\hline
\end{tabular}




\begin{tabular}{|c|c|c|c|}
\hline 14 & $\begin{array}{l}\text { Una economía transparente trae } \\
\text { calma a la población }\end{array}$ & $17-07-17$ & $\frac{\frac{\mathrm{https}: / / \text { www.eltelegrafo.com. }}{\text { ec/noticias/editoriales/1/una- }}}{\frac{\text { economia-transparente-trae- }}{\text { calma-a-la-poblacion }}}$ \\
\hline 15 & $\begin{array}{l}\text { La libertad de expresión como eje } \\
\text { de la democracia }\end{array}$ & $14-07-17$ & $\begin{array}{l}\frac{\mathrm{https}: / / \text { www.eltelegrafo.com. }}{\text { ec/noticias/editoriales/1/la- }} \\
\frac{\text { libertad-de-expresion-como- }}{\text { eje-de-la-democracia }}\end{array}$ \\
\hline 16 & $\begin{array}{l}\text { Carondelet muestra un significati- } \\
\text { vo gesto hacia la igualdad }\end{array}$ & $30-06-17$ & $\begin{array}{l}\frac{\text { https://www.eltelegrafo.com. }}{\text { ec/noticias/editoriales/1/ }} \\
\frac{\text { carondelet-muestra-un- }}{\text { significativo-gesto-hacia-la- }} \\
\text { igualdad }\end{array}$ \\
\hline 17 & $\begin{array}{l}\text { Primer mes del Gobierno con dos } \\
\text { promesas cumplidas }\end{array}$ & $24-06-17$ & $\begin{array}{l}\text { https://www.eltelegrafo.com. } \\
\text { ec/noticias/editoriales/1/ } \\
\text { primer-mes-de-gobierno-con- } \\
\text { dos-promesas-cumplidas }\end{array}$ \\
\hline 18 & $\begin{array}{l}\text { En diez años Ecuador dio un giro } \\
\text { hacia la estabilidad política }\end{array}$ & $24-05-17$ & $\begin{array}{l}\frac{\text { https://www.eltelegrafo.com. }}{\text { ec/noticias/editoriales/1/ }} \\
\frac{\text { en-diez-anos-ecuador-dio- }}{\text { un-giro-hacia-la-estabilidad- }} \\
\text { politica }\end{array}$ \\
\hline 19 & $\begin{array}{l}\text { Rafael Correa deja sus regalos al } \\
\text { pueblo ecuatoriano }\end{array}$ & $16-05-17$ & $\begin{array}{l}\frac{\text { https://www.eltelegrafo.com. }}{\text { ec/noticias/editoriales/1/ }} \\
\frac{\text { rafael-correa-deja-sus-regalos- }}{\underline{\text { al-pueblo-ecuatoriano }}}\end{array}$ \\
\hline 20 & $\begin{array}{l}\text { Un diálogo de buena fe y sin } \\
\text { condiciones previas }\end{array}$ & $08-05-17$ & $\begin{array}{l}\frac{\text { https://www.eltelegrafo.com. }}{\text { ec/noticias/editoriales/1/ }} \\
\frac{\text { un-dialogo-de-buena-fe-y-sin- }}{\text { condiciones-previas }}\end{array}$ \\
\hline 21 & $\begin{array}{l}\text { El bono de desarrollo se erige } \\
\text { como arma contra la pobreza }\end{array}$ & $04-05-17$ & $\begin{array}{l}\text { https://www.eltelegrafo.com. } \\
\text { ec/noticias/editoriales/1/el- } \\
\text { bono-de-desarrollo-se-erige- } \\
\text { como-arma-contra-la-pobreza }\end{array}$ \\
\hline 22 & $\begin{array}{l}\text { La verdad debe brillar para que el } \\
\text { país pase la página electoral }\end{array}$ & $27-04-17$ & $\begin{array}{l}\text { https://www.eltelegrafo.com. } \\
\text { ec/noticias/editoriales/1/ } \\
\text { la-verdad-debe-brillar-para- } \\
\text { que-el-pais-pase-la-pagina- } \\
\text { electoral }\end{array}$ \\
\hline 23 & $\begin{array}{l}\text { Las detenciones por el caso Ode- } \\
\text { brecht tumban una muletilla }\end{array}$ & 24-04-17 & $\begin{array}{l}\frac{\text { https://www.eltelegrafo.com. }}{\text { ec/noticias/editoriales/1/ }} \\
\frac{\text { las-detenciones-por-el-caso- }}{\text { odebrecht-tumban-una- }} \\
\text { muletilla }\end{array}$ \\
\hline
\end{tabular}




\begin{tabular}{|c|c|c|c|}
\hline 24 & $\begin{array}{l}\text { Un recuento inédito revela la } \\
\text { calidad de nuestra democracia }\end{array}$ & $21-04-17$ & $\begin{array}{l}\text { https://www.eltelegrafo.com. } \\
\text { ec/noticias/editoriales/1/ } \\
\text { un-recuento-inedito-revela-la- } \\
\text { calidad-de-nuestra-democracia }\end{array}$ \\
\hline 25 & $\begin{array}{l}\text { Se cierra un proceso y quedan lec- } \\
\text { ciones del país político-mediático }\end{array}$ & 20-04-17 & $\begin{array}{l}\text { https://www.eltelegrafo.com. } \\
\text { ec/noticias/editoriales/1/ } \\
\text { se-cierra-un-26proceso-y- } \\
\frac{\text { quedan-lecciones-del-pais- }}{\text { politico-mediatico }}\end{array}$ \\
\hline 26 & $\begin{array}{l}\text { Una economía en recuperación } \\
\text { alienta todo proceso político }\end{array}$ & 19-04-17 & $\begin{array}{l}\text { https://www.eltelegrafo.com. } \\
\text { ec/noticias/editoriales/1/una- } \\
\text { economia-en-recuperacion- } \\
\text { alienta-todo-proceso-politico }\end{array}$ \\
\hline 27 & $\begin{array}{c}\text { A Guillermo Lasso si le sirve la } \\
\text { LOC cuando de perseguirnos se } \\
\text { trata }\end{array}$ & 18-04-17 & $\begin{array}{l}\frac{\text { https://www.eltelegrafo.com. }}{\text { ec/noticias/editoriales/1/a- }} \\
\text { guillermo-lasso-si-le-sirve-la- } \\
\frac{\text { loc-cuando-de-perseguirnos- }}{\text { se-trata }}\end{array}$ \\
\hline 28 & $\begin{array}{l}\text { Más respeto por la voluntad popu- } \\
\text { lar y las instituciones públicas }\end{array}$ & 17-04-17 & $\begin{array}{l}\frac{\mathrm{https}: / / \text { www.eltelegrafo.com. }}{\text { ec/noticias/editoriales/1/ }} \\
\frac{\text { mas-respeto-por-la-voluntad- }}{\text { popular-y-las-instituciones- }} \\
\text { publicas }\end{array}$ \\
\hline 29 & $\begin{array}{l}\text { ¿A qué le llaman un país dividido } \\
\text { quienes desprecian al otro? }\end{array}$ & $14-04-17$ & $\begin{array}{l}\text { https://www.eltelegrafo.com. } \\
\text { ec/noticias/editoriales/1/a-que- } \\
\text { le-llaman-un-pais-dividido- } \\
\text { quienes-desprecian-al-otro }\end{array}$ \\
\hline 30 & $\begin{array}{l}\text { La confianza que pide el empresa- } \\
\text { riado es de obligaciones mutuas }\end{array}$ & $13-04-17$ & 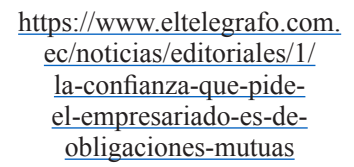 \\
\hline 31 & $\begin{array}{l}\text { El rol de los medios en los comi- } \\
\text { cios merece una gran investigación }\end{array}$ & $12-04-17$ & $\begin{array}{l}\text { https://www.eltelegrafo.com. } \\
\text { ec/noticias/editoriales/1/ } \\
\text { el-rol-de-los-medios-en-los- } \\
\frac{\text { comicios-merece-una-gran- }}{\text { investigacion }}\end{array}$ \\
\hline 32 & $\begin{array}{l}\text { Las "señales claras" que piden el } \\
\text { mercado y los poderes fácticos }\end{array}$ & $11-04-17$ & $\begin{array}{l}\frac{\mathrm{https}: / / \text { www.eltelegrafo.com. }}{\mathrm{ec} / \text { noticias/editoriales/1/ }} \\
\frac{\text { las-senales-claras-que-piden- }}{\text { el-mercado-y-los-poderes- }} \\
\text { facticos }\end{array}$ \\
\hline
\end{tabular}




\begin{tabular}{|c|c|c|c|}
\hline 33 & $\begin{array}{l}\text { ¿Los hechos ya no existen para } \\
\text { algunos políticos y medios” }\end{array}$ & 09-04-17 & $\begin{array}{l}\underline{\text { https://www.eltelegrafo.com. }} \\
\text { ec/noticias/editoriales/1/los- } \\
\text { hechos-ya-no-existen-para- } \\
\text { algunos-politicos-y-medios }\end{array}$ \\
\hline 34 & $\begin{array}{l}\text { Ese afán de buscan en la fuerza } \\
\text { pública una respuesta ilegítima }\end{array}$ & 08-04-17 & $\begin{array}{l}\frac{\text { https://www.eltelegrafo.com. }}{\text { ec/noticias/editoriales/1/ }} \\
\text { ese-afan-de-buscar-35en-la- } \\
\text { fuerza-publica-una-respuesta- } \\
\text { ilegitima }\end{array}$ \\
\hline 35 & $\begin{array}{l}\text { Un reconocimiento mundial a un } \\
\text { proceso político transparente }\end{array}$ & 07-04-17 & $\begin{array}{l}\underline{\mathrm{https}: / / \text { www.eltelegrafo.com. }} \\
\text { ec/noticias/editoriales/1/un- } \\
\text { reconocimiento-mundial-a-un- } \\
\text { proceso-politico-transparente }\end{array}$ \\
\hline 36 & $\begin{array}{l}\text { Alcalde Rodas, no deje a la capital } \\
\text { en manos del caos y la violencia }\end{array}$ & 06-04-17 & $\begin{array}{l}\frac{\text { https://www.eltelegrafo.com. }}{\text { ec/noticias/editoriales/1/ }} \\
\frac{\text { alcalde-rodas-no-deje-a-la- }}{\text { capital-en-manos-del-caos-y- }} \\
\text { la-violencia }\end{array}$ \\
\hline 37 & $\begin{array}{l}\text { El rol de los exit polls debe ser } \\
\text { bien revisado }\end{array}$ & 05-04-17 & $\begin{array}{l}\frac{\text { https://www.eltelegrafo.com. }}{\mathrm{ec} / \text { noticias/editoriales/1/ }} \\
\frac{\text { el-rol-de-los-exit-polls-y-las- }}{\text { encuestadoras-debe-ser-bien- }} \\
\text { revisado }\end{array}$ \\
\hline 38 & $\begin{array}{l}\text { Ecuador demostró su vocación } \\
\text { democrática para forjar su futuro }\end{array}$ & 04-04-17 & $\begin{array}{l}\frac{\text { https://www.eltelegrafo.com. }}{\text { ec/noticias/editoriales/1/ }} \\
\frac{\text { ecuador-demostro-su- }}{\text { vocacion-democratica-para- }} \\
\text { forjar-su-futuro }\end{array}$ \\
\hline 39 & $\begin{array}{l}\text { El espíritu del intenso proceso } \\
\text { constituyente debe continuar }\end{array}$ & 02-04-17 & $\begin{array}{l}\text { https://www.eltelegrafo.com. } \\
\text { ec/noticias/editoriales/1/el- } \\
\text { espiritu-del-intenso-proceso- } \\
\text { constituyente-debe-continuar }\end{array}$ \\
\hline 40 & $\begin{array}{l}\text { La violencia electoral debe ser } \\
\text { desterrada en todos sus métodos }\end{array}$ & $30-03-17$ & $\begin{array}{l}\frac{\text { https://www.eltelegrafo.com. }}{\text { ec/noticias/editoriales/1/ }} \\
\text { la-violencia-electoral-debe- } \\
\frac{\text { ser-desterrada-en-todos-sus- }}{\text { metodos }}\end{array}$ \\
\hline 41 & $\begin{array}{l}\text { ¿Por qué usan la dolarización } \\
\text { como arma proselitista? }\end{array}$ & 29-03-17 & $\begin{array}{l}\frac{\mathrm{https}: / / \text { www.eltelegrafo.com. }}{\mathrm{ec} / \text { noticias/editoriales/1/ }} \\
\text { por-que-usan-la-dolarizacion- } \\
\text { como-arma-proselitista }\end{array}$ \\
\hline
\end{tabular}




\begin{tabular}{|c|c|c|c|}
\hline 42 & $\begin{array}{l}\text { Graves revelaciones de las que no } \\
\text { se ocupa ni explica la prensa }\end{array}$ & $28-03-17$ & $\begin{array}{l}\frac{\text { https://www.eltelegrafo.com. }}{\text { ec/noticias/editoriales/1/ }} \\
\text { graves-revelaciones-de-las- } \\
\text { que-no-se-ocupa-ni-explica- } \\
\text { la-prensa }\end{array}$ \\
\hline 43 & $\begin{array}{l}\text { La conducta y política mediática } \\
\text { privada deja una pobre lección }\end{array}$ & $27-03-17$ & $\begin{array}{l}\frac{\text { https://www.eltelegrafo.com. }}{\text { ec/noticias/editoriales/1/la- }} \\
\frac{\text { conducta-y-politica-mediatica- }}{\text { privada-deja-una-pobre- }} \\
\text { leccion }\end{array}$ \\
\hline 44 & $\begin{array}{l}\text { Ecuador vive un momento clave } \\
\text { de definiciones históricas }\end{array}$ & 26-03-17 & $\begin{array}{l}\frac{\text { https://www.eltelegrafo.com. }}{\text { ec/noticias/editoriales/1/ }} \\
\frac{\text { ecuador-vive-un-momento- }}{\text { clave-de-definiciones- }} \\
\frac{\text { historicas }}{}\end{array}$ \\
\hline 45 & $\begin{array}{l}\text { La 'inmunidad' de un candidato no } \\
\text { es licencia para desestabilizar }\end{array}$ & $25-03-17$ & $\begin{array}{l}\frac{\text { https://www.eltelegrafo.com. }}{\mathrm{ec} / \text { noticias/editoriales/1/ }} \\
\text { la-inmunidad-de-un- } \\
\text { candidato-no-es-licencia-para- } \\
\text { desestabilizar }\end{array}$ \\
\hline 46 & $\begin{array}{l}\text { Las redes sociales no deben ni } \\
\text { pueden ser el basurero de la po- } \\
\text { lítica }\end{array}$ & 24-03-17 & $\begin{array}{l}\frac{\text { https://www.eltelegrafo.com. }}{\text { ec/noticias/editoriales/1/ }} \\
\text { las-redes-sociales-no-deben- } \\
\underline{\text { ni-pueden-ser-el-basurero-de- }} \\
\underline{\text { la-politica }}\end{array}$ \\
\hline 47 & $\begin{array}{l}\text { El control electoral no le da a } \\
\text { nadie privilegio sobre el CNE }\end{array}$ & $23-03-17$ & $\begin{array}{l}\frac{\mathrm{https}: / / \text { www.eltelegrafo.com. }}{\mathrm{ec} / \text { noticias/editoriales/1/ }} \\
\text { el-control-electoral-no-le-da-} \\
\text { a-nadie-privilegio-ni-derecho- } \\
\text { sobre-cne }\end{array}$ \\
\hline 48 & $\begin{array}{l}\text { ¿Lista de Odebrecht debe ser tari- } \\
\text { ma de la campaña electoral? }\end{array}$ & 21-03-17 & $\begin{array}{l}\frac{\text { https://www.eltelegrafo.com. }}{\text { ec/noticias/editoriales/1/ }} \\
\text { la-lista-de-odebrecht-debe- } \\
\text { ser-la-tarima-de-la-campana- } \\
\text { electoral }\end{array}$ \\
\hline 49 & $\begin{array}{l}\text { La campaña sucia no empezó este } \\
\text { año, lleva más de una década }\end{array}$ & $20-03-17$ & $\begin{array}{l}\frac{\mathrm{https}: / / \text { www.eltelegrafo.com. }}{\mathrm{ec} / \text { noticias/editoriales/1/ }} \\
\frac{\text { la-campana-sucia-no-empezo- }}{\text { este-ano-lleva-mas-de-una- }} \\
\underline{\text { decada }}\end{array}$ \\
\hline 50 & $\begin{array}{l}\text { La recuperación de la economía y } \\
\text { las presidenciales }\end{array}$ & 19-03-17 & $\begin{array}{l}\frac{\mathrm{https}: / / \text { www.eltelegrafo.com. }}{\text { ec/noticias/editoriales/1/la- }} \\
\text { recuperacion-de-la-economia- } \\
\text { y-las-presidenciales }\end{array}$ \\
\hline
\end{tabular}




\begin{tabular}{|c|c|c|c|}
\hline 51 & $\begin{array}{l}\text { Todavía queda mucho por contar y } \\
\text { explicar del feriado bancario }\end{array}$ & $18-03-17$ & $\begin{array}{l}\frac{\text { https://www.eltelegrafo.com. }}{\text { ec/noticias/editoriales/1/ }} \\
\frac{\text { todavia-queda-mucho-por- }}{\text { contar-y-explicar-del-feriado- }} \\
\text { bancario }\end{array}$ \\
\hline 52 & $\begin{array}{c}\text { Ecuador es Ecuador y no se } \\
\text { compara ni para estigmatizarlo si } \\
\text { quiera }\end{array}$ & $17-03-17$ & $\begin{array}{l}\text { https://www.eltelegrafo.com. } \\
\text { ec/noticias/editoriales/1/ } \\
\text { ecuador-es-ecuador-y- } \\
\text { no-se-compara-ni-para- } \\
\text { estigmatizarlo-siquiera }\end{array}$ \\
\hline 53 & $\begin{array}{l}\text { El uso proselitista de la 'lista de } \\
\text { Odebrecht' quizá traiga sorpresas }\end{array}$ & $16-03-17$ & $\begin{array}{l}\frac{\text { https://www.eltelegrafo.com. }}{\text { ec/noticias/editoriales/1/ }} \\
\frac{\text { el-uso-proselitista-de-la- }}{\text { lista-odebrecht-quiza-traiga- }} \\
\text { sorpresas }\end{array}$ \\
\hline 54 & $\begin{array}{l}\text { El repunte económico de Ecuador } \\
\text { augura otro escenario social }\end{array}$ & $15-03-17$ & $\begin{array}{c}\frac{\mathrm{https}: / / \text { www.eltelegrafo.com. }}{\mathrm{ec} / \text { noticias/editoriales/1/ }} \\
\frac{\text { el-repunte-economico- }}{\text { de-ecuador-augura-otro- }} \\
\frac{\text { escenario-social }}{}\end{array}$ \\
\hline 55 & $\begin{array}{l}\text { La zona cero queda atrás y Porto- } \\
\text { viejo va por su progreso social }\end{array}$ & 14-03-17 & $\begin{array}{c}\text { https://www.eltelegrafo.com. } \\
\underline{\text { ec/noticias/editoriales/1/ }} \\
\begin{array}{c}\text { la-zona-cero-queda-atras- } \\
\text { y-portoviejo-va-por-su- } \\
\text { progreso-social }\end{array}\end{array}$ \\
\hline 56 & $\begin{array}{l}\text { ¿Por qué Rodas vota contra la } \\
\text { ordenanza antitaurina en Quito? }\end{array}$ & $13-03-17$ & $\begin{array}{l}\text { https://www.eltelegrafo.com. } \\
\text { ec/noticias/editoriales/1/por- } \\
\text { que-rodas-vota-contra-de-la- } \\
\text { ordenanza-antitaurina-en-quito }\end{array}$ \\
\hline 57 & $\begin{array}{l}\text { La moral sin ética se cuela en } \\
\text { izquierdas y derechas extremas }\end{array}$ & $12-03-17$ & $\begin{array}{l}\text { https://www.eltelegrafo.com. } \\
\text { ec/noticias/editoriales/1/ } \\
\frac{\text { la-moral-sin-etica-se-cuela- }}{\text { en-izquierdas-y-derechas- }} \\
\text { extremas }\end{array}$ \\
\hline 58 & $\begin{array}{l}\text { Mauricio Rodas debe pronunciarse } \\
\text { sobre el caso Odebrecht }\end{array}$ & $11-03-17$ & $\begin{array}{c}\frac{\mathrm{https}: / / \text { www.eltelegrafo.com. }}{\mathrm{ec} / \text { noticias/editoriales/1/ }} \\
\text { mauricio-rodas-debe- } \\
\text { pronunciarse-sobre-el- } \\
\text { escandalo-odebrecht }\end{array}$ \\
\hline 59 & $\begin{array}{l}\text { El feriado bancario no es una fic- } \\
\text { ción y tiene víctimas por millones }\end{array}$ & $10-03-17$ & $\begin{array}{l}\frac{\text { https://www.eltelegrafo.com. }}{\text { ec/noticias/editoriales/1/ }} \\
\frac{\text { el-feriado-bancario-no-es-una- }}{\text { ficcion-y-tiene-victimas-por- }} \\
\text { millones }\end{array}$ \\
\hline
\end{tabular}




\begin{tabular}{|c|c|c|c|}
\hline 60 & $\begin{array}{l}\text { No a la amenaza contra los perio- } \\
\text { distas de los medios públicos }\end{array}$ & $09-03-17$ & $\begin{array}{l}\frac{\text { https://www.eltelegrafo.com. }}{\text { ec/noticias/editoriales/1/ }} \\
\frac{\text { no-a-la-amenaza-contra-los- }}{\text { periodistas-de-los-medios- }} \\
\text { publicos }\end{array}$ \\
\hline 61 & $\begin{array}{l}\text { La sabiduría de Nebot explica por } \\
\text { qué lo quieren Lasso y Páez }\end{array}$ & 06-03-17 & $\begin{array}{l}\frac{\text { https://www.eltelegrafo.com. }}{\text { ec/noticias/editoriales/1/ }} \\
\frac{\text { la-sabiduria-de-nebot-explica- }}{\text { el-porque-lo-requieren-lasso- }} \\
\text { y-paez }\end{array}$ \\
\hline 62 & $\begin{array}{l}\text { ¿La agenda política de Lasso } \\
\text { incluye al hombre del maletín? }\end{array}$ & $05-03-17$ & $\begin{array}{l}\text { https://www.eltelegrafo.com. } \\
\text { ec/noticias/editoriales/1/ } \\
\text { la-agenda-politica-de-lasso- } \\
\text { incluye-al-hombre-del-maletin }\end{array}$ \\
\hline 63 & $\begin{array}{l}\text { Las agresiones al CNE y el uso de } \\
\text { niños no puede quedar impune }\end{array}$ & 04-03-17 & $\begin{array}{l}\frac{\text { https://www.eltelegrafo.com. }}{\text { ec/noticias/editoriales/1/las- }} \\
\frac{\text { agresiones-al-cne-y-el-uso- }}{\text { de-ninos-no-puede-quedar- }} \\
\text { impune }\end{array}$ \\
\hline 64 & $\begin{array}{l}\text { ¿Por qué la oposición no denuncia } \\
\text { el fraude del que tanto habla? }\end{array}$ & $02-03-17$ & $\begin{array}{l}\text { https://www.eltelegrafo.com. } \\
\text { ec/noticias/editoriales/1/por- } \\
\text { que-la-oposicion-no-denuncia- } \\
\text { el-fraude-del-que-tanto-habla }\end{array}$ \\
\hline 65 & $\begin{array}{l}\text { Llaman a incendiar Quito ¿Y el } \\
\text { Alcalde Rodas? ¡Bien, gracias! }\end{array}$ & $26-02-17$ & $\begin{array}{l}\frac{\text { https://www.eltelegrafo.com. }}{\text { ec/noticias/editoriales/1/ }} \\
\frac{\text { llaman-a-incendiar-quito-y-el- }}{\text { alcalde-rodas-bien-gracias }}\end{array}$ \\
\hline 66 & $\begin{array}{l}\text { Brasil y Argentina son los espejos } \\
\text { donde hay que mirar el presente }\end{array}$ & $25-02-17$ & $\begin{array}{l}\frac{\text { https://www.eltelegrafo.com. }}{\text { ec/noticias/editoriales/1/ }} \\
\frac{\text { brasil-y-argentina-son-los- }}{\text { espejos-donde-hay-que-mirar- }} \\
\text { el-presente }\end{array}$ \\
\hline 67 & $\begin{array}{l}\text { La oposición necesita ser más } \\
\text { responsable con sus partidarios }\end{array}$ & $22-02-17$ & $\begin{array}{l}\frac{\text { https://www.eltelegrafo.com. }}{\text { ec/noticias/editoriales/1/ }} \\
\frac{\text { la-oposicion-necesita-ser- }}{\text { mas-responsable-con-sus- }} \\
\text { partidarios }\end{array}$ \\
\hline 68 & $\begin{array}{l}\text { Una democracia plena para los } \\
\text { grandes retos y anhelos populares }\end{array}$ & $20-02-17$ & $\begin{array}{l}\frac{\text { https://www.eltelegrafo.com. }}{\text { ec/noticias/editoriales/1/ }} \\
\frac{\text { una-democracia-plena-para- }}{\text { los-grandes-retos-y-anhelos- }} \\
\text { populares }\end{array}$ \\
\hline
\end{tabular}




\begin{tabular}{|c|c|c|c|}
\hline 69 & $\begin{array}{l}\text { El silencio de Odebrecht frente } \\
\text { al bullicio de los candidatos y } \\
\text { 'analistas' }\end{array}$ & $18-02-17$ & $\begin{array}{l}\frac{\text { https://www.eltelegrafo.com. }}{\text { ec/noticias/editoriales/1/el- }} \\
\frac{\text { silencio-de-odebrecht-frente- }}{\text { al-bullicio-de-los-candidatos- }} \\
y \text { y-analistas }\end{array}$ \\
\hline 70 & $\begin{array}{l}\text { ¿Qué esconde Rodas al no inscri- } \\
\text { bir los contratos del SERCOP? }\end{array}$ & $14-02-17$ & $\begin{array}{l}\frac{\mathrm{https}: / / \text { www.eltelegrafo.com. }}{\text { ec/noticias/editoriales/1/que- }} \\
\frac{\text { esconde-rodas-al-no-inscribir- }}{\text { los-contratos-en-sercop }}\end{array}$ \\
\hline 71 & $\begin{array}{l}\text { ¿Algunas mentiras de ciertos can- } \\
\text { didatos se deben pasar por alto? }\end{array}$ & $09-02-17$ & $\begin{array}{l}\frac{\text { https://www.eltelegrafo.com. }}{\text { ec/noticias/editoriales/1/ }} \\
\frac{\text { algunas-mentiras-de-ciertos- }}{\text { candidatos-se-deben-pasar- }} \\
\text { por-alto }\end{array}$ \\
\hline 72 & $\begin{array}{l}\text { ¿Dónde está «Capaya' que la pren- } \\
\text { sa 'libre' llega y la Interpol no? }\end{array}$ & $07-02-17$ & $\begin{array}{c}\text { https://www.eltelegrafo.com. } \\
\frac{\text { ec/noticias/editoriales/1/ }}{\text { donde-esta-capaya-que- }} \\
\frac{\text { la-prensa-libre-llega-y-la- }}{\text { interpol-no }}\end{array}$ \\
\hline 73 & $\begin{array}{l}\text { ¿Cuánto poder ejercen todavía los } \\
\text { Isaías en la prensa? }\end{array}$ & $06-02-17$ & $\begin{array}{l}\frac{\text { https://www.eltelegrafo.com. }}{\text { ec/noticias/editoriales/1/ }} \\
\frac{\text { cuanto-poder-ejercen-todavia- }}{\text { los-isaias-en-la-prensa }}\end{array}$ \\
\hline 74 & $\begin{array}{l}\text { Prefectura de Azuay: La falsa des- } \\
\text { calificación por ser medio público }\end{array}$ & $27-01-17$ & $\begin{array}{l}\text { https://www.eltelegrafo.com. } \\
\text { ec/noticias/editoriales/1/ } \\
\text { prefectura-de-azuay-la-falsa- } \\
\frac{\text { descalificacion-por-ser-medio- }}{\text { publico }}\end{array}$ \\
\hline 75 & $\begin{array}{l}\text { Odebrecht: Capítulos que se le ol- } \\
\text { vidaron al departamento de justicia }\end{array}$ & $19-01-17$ & $\begin{array}{l}\frac{\text { https://www.eltelegrafo.com. }}{\text { ec/noticias/editoriales/1/ }} \\
\frac{\text { odebrecht-capituloslos-que-se- }}{\text { le-olidaron-al-departamento- }} \\
\text { de-justicia }\end{array}$ \\
\hline 76 & $\begin{array}{l}15 \text { de enero de 2017: un día de } \\
\text { celebración y advertencia política }\end{array}$ & $16-01-17$ & $\begin{array}{l}\frac{\text { https://www.eltelegrafo.com. }}{\text { ec/noticias/editoriales/1/15- }} \\
\frac{\text { de-enero-de-2017-un-dia-de- }}{\text { celebracion-y-advertencia- }} \\
\text { politica }\end{array}$ \\
\hline 77 & $\begin{array}{c}\text { 2007-2017: los cambios que se } \\
\text { ven y se siente }\end{array}$ & $15-01-17$ & $\begin{array}{l}\frac{\mathrm{https}: / / \text { www.eltelegrafo.com. }}{\text { ec/noticias/editoriales/1/2007- }} \\
\frac{2017 \text {-los-cambios-que-se-ven- }}{\text { y-se-sienten }}\end{array}$ \\
\hline
\end{tabular}




\begin{tabular}{|c|c|c|c|}
\hline 78 & $\begin{array}{l}\text { Lasso: Desde el pollo pelado hasta } \\
\text { la alergia electoral hacia Rodas }\end{array}$ & $14-01-17$ & $\begin{array}{l}\frac{\text { https://www.eltelegrafo.com. }}{\text { ec/noticias/editoriales/1/ }} \\
\frac{\text { lasso-desde-el-pollo-pelado- }}{\text { hasta-la-alergia-electoral- }} \\
\text { hacia-rodas }\end{array}$ \\
\hline 79 & $\begin{array}{l}\text { El comunicado leído por el alcalde } \\
\text { Rodas: Una pieza de colección }\end{array}$ & $11-01-17$ & $\begin{array}{l}\frac{\text { https://www.eltelegrafo.com. }}{\mathrm{ec} / \text { noticias/editoriales/1/ }} \\
\frac{\text { el-comunicado-leido-por-el- }}{\text { alcalde-rodas-una-pieza-de- }} \\
\underline{\text { coleccion }}\end{array}$ \\
\hline 80 & $\begin{array}{l}\text { Dolarización: De la realidad histó- } \\
\text { rica a los agoreros del desastre }\end{array}$ & $10-01-17$ & $\begin{array}{l}\frac{\text { https://www.eltelegrafo.com. }}{\text { ec/noticias/editoriales/1/ }} \\
\frac{\text { dolarizacion-de-la-realidad- }}{\text { historica-a-los-agoreros-del- }} \\
\text { desastre }\end{array}$ \\
\hline 81 & $\begin{array}{l}\text { La frase hueca se queda cada vez } \\
\text { con menos eco electoral }\end{array}$ & 08-01-17 & $\begin{array}{l}\text { https://www.eltelegrafo.com. } \\
\underline{\text { ec/noticias/editoriales/1/ }} \\
\text { la-frase-hueca-se-queda-cada- } \\
\text { vez-con-menos-eco-electoral }\end{array}$ \\
\hline 82 & $\begin{array}{l}\text { ¿Qué significa que una joven de } \\
31 \text { años ocupe la presidencia? }\end{array}$ & $07-01-17$ & $\begin{array}{l}\underline{\text { https://www.eltelegrafo.com. }} \\
\underline{\text { ec/noticias/editoriales/1/ }} \\
\text { la-frase-hueca-se-queda-cada- } \\
\text { vez-con-menos-eco-electoral }\end{array}$ \\
\hline 83 & $\begin{array}{l}\text { ¿Qué se juega en las elecciones } \\
\text { generales del } 19 \text { de febrero? }\end{array}$ & 03-01-17 & $\begin{array}{l}\text { https://www.eltelegrafo.com. } \\
\text { ec/noticias/editoriales/1/que- } \\
\text { se-juega-en-las-elecciones- } \\
\text { generales-del-19-de-febrero }\end{array}$ \\
\hline
\end{tabular}

\section{Fuente: Elaboración propia}

\section{Cuadro 3}

\section{Editoriales Diario El Telégrafo año 2018}

\begin{tabular}{|c|c|c|c|}
\hline No. & EDITORIAL & FECHA & LINK \\
\hline 1 & Hasta derrotar la corrupción & $31-12-18$ & $\begin{array}{l}\text { https://www.eltelegrafo.com. } \\
\text { ec/noticias/editoriales/1/has- } \\
\text { ta-derrotar-a-la-corrupcion }\end{array}$ \\
\hline 2 & $\begin{array}{l}\text { La gasolina en Ecuador es de las } \\
\text { más baratas de Latinoamérica }\end{array}$ & $24-12-18$ & $\begin{array}{l}\frac{\text { https://www.eltelegrafo.com. }}{\text { ec/noticias/editoriales/1/ }} \\
\frac{\text { la-gasolina-en-ecuador-es- }}{\text { de-las-mas-baratas-de-lati- }} \\
\text { noamerica }\end{array}$ \\
\hline
\end{tabular}




\begin{tabular}{|c|c|c|c|}
\hline 3 & $\begin{array}{l}\text { La Ley de Comunicación da un giro } \\
\text { al ejercicio del periodismo }\end{array}$ & $20-12-18$ & $\begin{array}{l}\text { https://www.eltelegrafo.com. } \\
\frac{\text { ec/noticias/editoriales/1/ }}{\text { ley-comunicacion-ejerci- }} \\
\underline{\text { cio-periodismo-ecuador }}\end{array}$ \\
\hline 4 & $\begin{array}{l}\text { Con un mensaje conciliador asume } \\
\text { Otto Sonnenholzner }\end{array}$ & $12-12-18$ & $\begin{array}{l}\frac{\text { https://www.eltelegrafo.com. }}{\text { ec/noticias/editoriales/1/ }} \\
\frac{\text { ottosonnenholzner-vicpresi- }}{\text { dente-ecuador }}\end{array}$ \\
\hline 5 & $\begin{array}{l}\text { Los venezolanos exiliados en el } \\
\text { Ecuador agradecen a Moreno }\end{array}$ & 20-10-18 & $\begin{array}{l}\frac{\text { https://www.eltelegrafo.com. }}{\text { ec/noticias/editoriales/1/ }} \\
\frac{\text { venezolanos-exiliados-lenin- }}{\text { moreno-ecuador }}\end{array}$ \\
\hline 6 & $\begin{array}{l}\text { Un frontal rechazo de Moreno al } \\
\text { "socialismo corrupto" }\end{array}$ & 11-10-18 & $\begin{array}{l}\frac{\text { https://www.eltelegrafo.com. }}{\text { ec/noticias/editoriales/1/ }} \\
\text { rechazo-frontal-leninmore- } \\
\underline{\text { no-socialismo-corrupto }}\end{array}$ \\
\hline 7 & $\begin{array}{l}\text { Ecuador, país confiable para la } \\
\text { inversión extranjera }\end{array}$ & $01-10-18$ & $\frac{\text { https://www.eltelegrafo.com. }}{\frac{\text { ec/noticias/editoriales/1/ }}{\text { ecuador-confiable-inver- }}}$ \\
\hline 8 & $\begin{array}{l}\text { La salida de la ALBA y una propues- } \\
\text { ta de soluciones }\end{array}$ & $25-08-18$ & $\begin{array}{l}\frac{\text { https://www.eltelegrafo.com. }}{\text { ec/noticias/editoriales/1/ }} \\
\frac{\text { ecuador-salida-alba-propues- }}{\text { ta-soluciones }}\end{array}$ \\
\hline 9 & $\begin{array}{c}\text { Resultados positivos se advierten en } \\
\text { la economía }\end{array}$ & 14-08-18 & $\begin{array}{l}\frac{\text { https://www.eltelegrafo.com. }}{\text { ec/noticias/editoriales/1/ }} \\
\frac{\text { resultados-positivos-econo- }}{\text { mia-ecuador }}\end{array}$ \\
\hline 10 & $\begin{array}{l}\text { Moreno: Salir del abismo y construir } \\
\text { un presente digno }\end{array}$ & $28-07-18$ & $\begin{array}{l}\frac{\text { https://www.eltelegrafo.com. }}{\text { ec/noticias/editoriales/1/ }} \\
\frac{\text { moreno-gira-presiden- }}{\text { cial-europa }}\end{array}$ \\
\hline 11 & $\begin{array}{l}\text { El rol del nuevo CNE en las elec- } \\
\text { ciones del } 2019\end{array}$ & 19-07-18 & $\begin{array}{l}\text { https://www.eltelegrafo.com. } \\
\underline{\text { ec/noticias/editoriales/1/rol- }} \\
\underline{\text { nuevo-cne-elecciones } 2019}\end{array}$ \\
\hline 12 & $\begin{array}{l}\text { La verdad sobre la libertad de ex- } \\
\text { presión en el Ecuador }\end{array}$ & $14-07-18$ & $\begin{array}{l}\frac{\text { https://www.eltelegrafo.com. }}{\text { ec/noticias/editoriales/1/ }} \\
\frac{\text { periodismo-libertad-expre- }}{\text { sion-ecuador }}\end{array}$ \\
\hline 13 & $\begin{array}{l}\text { Ecuador reitera su postura sobre } \\
\text { política internacional }\end{array}$ & 06-07-18 & $\begin{array}{l}\text { https://www.eltelegrafo.com. } \\
\frac{\text { ec/noticias/editoriales/1/ }}{\text { ecuador-postura-politica-in- }} \\
\text { ternacional }\end{array}$ \\
\hline
\end{tabular}




\begin{tabular}{|c|c|c|c|}
\hline 14 & $\begin{array}{l}\text { Un clima de confianza que atrae a la } \\
\text { inversión extranjera }\end{array}$ & $18-06-18$ & $\begin{array}{l}\frac{\text { https://www.eltelegrafo.com. }}{\text { ec/noticias/editoriales/1/cli- }} \\
\frac{\text { ma-confianza-inversion-ex- }}{\text { tranjera }}\end{array}$ \\
\hline 15 & $\begin{array}{l}\text { Un vistazo a los primeros } 365 \text { días } \\
\text { de Lenin Moreno en el poder }\end{array}$ & $23-05-18$ & $\begin{array}{l}\frac{\text { https://www.eltelegrafo.com. }}{\mathrm{ec} / \text { noticias/editoriales/1/ }} \\
\frac{\text { lenin-moreno-primer-ano-in- }}{\text { forme-nacion }}\end{array}$ \\
\hline 16 & $\begin{array}{l}\text { Las Manuelas, a la vanguardia en el } \\
\text { tema de las capacidades }\end{array}$ & 23-05-18 & $\begin{array}{l}\frac{\text { https://www.eltelegrafo.com. }}{\text { ec/noticias/editoriales/1/ }} \\
\frac{\text { las-manuelas-a-la-vanguar- }}{\text { dia-en-el-tema-de-discapaci- }} \\
\text { dades }\end{array}$ \\
\hline 17 & $\begin{array}{l}\text { Trujillo recibe respaldo oficial y } \\
\text { también de la ciudadanía }\end{array}$ & 09-05-18 & $\begin{array}{l}\frac{\text { https://www.eltelegrafo.com. }}{\text { ec/noticias/editoriales/1/ }} \\
\frac{\text { trujillo-recibe-respaldo-ofi- }}{\text { cial-y-tambien-de-la-ciu- }} \\
\text { dadania }\end{array}$ \\
\hline 18 & $\begin{array}{l}\text { Los medios públicos consolidan su } \\
\text { línea democrática y plural }\end{array}$ & 14-02-18 & $\begin{array}{l}\frac{\text { https://www.eltelegrafo.com. }}{\text { ec/noticias/editoriales/1/ }} \\
\frac{\text { los-medios-publicos-con- }}{\text { solidan-su-linea-democrati- }} \\
\text { ca-y-plural }\end{array}$ \\
\hline
\end{tabular}

Fuente: Elaboración propia

\section{Conclusiones}

- El desarrollo teórico y análisis de caso demuestra que al Ecuador le falta experiencia en el manejo de medios públicos, por lo que es necesario mayor debate, así como un proceso de aprendizaje y práctica del tema.

- Lo público debe ser entendido como un espacio común a todos, no es lo estatal, ni lo gubernamental, peor aún lo privado. En ese sentido, el país requiere medios públicos comprometidos con su realidad, no basados en esquemas ni en estereotipos determinados, sino en un camino propio que permita democratizar, desprivatizar y ampliar la opinión pública.

- La importancia de los medios públicos radica en crear y abrir espacios 
de difusión de la opinión pública ciudadana, no en una opinión que pueda ser publicada por los grandes intereses del país -sean políticos o económicos- así, es claro que estos medios son ciudadanos y no de un gobierno o partido político.

- El desconocimiento del concepto de diario público en el Ecuador ha llevado a que Diario El Telégrafo sea utilizado como una herramienta de difusión de su gestión política y no como un medio periodístico complementario a la información que brindan los diarios privados. Las ediciones previas a las elecciones presidenciales en 2017 así lo demuestran.

- El difundir y resaltar las apariciones de mandatarios o representantes de gobierno ha generado una saturación informativa, considerando que existe un desarrollo de contenidos que se da de manera frecuente en los medios privados.

- En necesario que los nuevos medios públicos tengan un papel protagónico en el desarrollo tecnológico, a fin de que puedan ser una alternativa real a la producción de carácter privado.

- Tanto medios públicos como privados compiten por una misma audiencia sin que exista una propuesta diferente y creativa, que les permita a los medios independientemente de su origen cumplir con su función tradicional y fundamental: informar, educar y entretener, valores que fomentan los medios de comunicación en general.

- No se implementó entre los años 2017 y 2018 una revisión prolija de las políticas de gestión administrativa y periodística de los medios de comunicación públicos en el Ecuador, a fin de que el ciudadano común pueda valorar la verdadera importancia de los mismos. 


\section{Bibliografía}

Abad, Gustavo (2011). "El club de la pelea. Gobierno y medios, un entramado de fuerzas y debilidades". Veeduría Ciespal. Ecuador.

Asamblea General del Consejo de Europa. Código Europeo de Deontología del Periodismo. 1 de julio de 1993. Artículo 5to.

Ayala, E. (1982). "La prensa en la historia del Ecuador, una breve visión general”. En C. Destrugue (Comp.) Historia de la prensa en Guayaquil. Corporación Editora Nacional. Quito.

Biografías y vidas (s/f) Bernard Berelson [En línea] Disponible en: http://www.biografiasyvidas.com/biografia/b/berelson.htm

Biografías y vidas (s/f) Marshall McLuhan [En línea] Disponible en: http://www.biografiasyvidas.com/biografia/m/mcluhan.htm

Buitrón, Rubén Darío (2016). "Doce reflexiones sobre los medios públicos y la democracia" https://rubendariobuitron.wordpress.com/2016/03/31/ doce-reflexiones-sobre-medios-publicos-y-democracia/ 12/12/2018

CIESPAL (2009). "Percepción sobre los medios públicos en Ecuador”. Área de investigación. Quito.

Dahl, Robert (1999). La democracia, una guía para los ciudadanos. Buenos Aires, Taurus.

De Moraes, D. (2011). La cruzada de los medios en América Latina: gobiernos progresistas y políticas de comunicación. 1ra edición. Paidós, Buenos Aires.

Diario El Telégrafo. "Sí existe mañana para los Medios Públicos" https://www.eltelegrafo.com.ec/noticias/medios/1/si-existe-manana-para-los-medios-publicos 
Diario El Telégrafo. "Los Medios Públicos se renuevan para la ciudadanía"

http://www.eltelegrafo.com.ec/noticias/medios/1/los-medios-publicos-se-renuevan-para-la-ciudadania

Diario El Comercio. “100 millones reciben al año los medios públicos en Ecuador"

http://www.elcomercio.com/actualidad/presupuesto-medios-publicos-andresmichelena-hernanramos.html Consulta: 12/12/2018

Diario La Hora. "Medios públicos: una idea en construcción” https:// lahora.com.ec/noticia/1102131951/medios-publicos-una-idea-en-construccion Consulta: 12/12/2018

Djeredjlan, E. (2007). "Harold Lasswell. Teoría de la comunicación. Material de estudio y complemento didáctico para las cátedras de "Teoría de la comunicación social" de la Universidad Católica Argentina (UCA). [En línea] Disponible en: http://teocoms.blogspot.com/2007/07/harold-dwight-lasswell-1902-1978.html

"Elecciones y medios de comunicación". En Red de Conocimientos Electorales https://aceproject.org/ace-es/topics/me/onePage Revisado el 16 de enero de 2019

Fundamedios (2009). "La palabra rota. Seis investigaciones sobre el periodismo ecuatoriano". Editor Fundamedios. Ecuador.

Infoamérica (s/f). Jesús Martín Barbero. Perfil bibliográfico y académico [En línea] Disponible en: http://www.infoamerica.org/teoria/martin barbero1.htm

Instituto de Estudios para la Transición Democrática. "Medios públicos esenciales en una sociedad democrática". http://www.ietd.org. mx/medios-publicos-esenciales-en-una-sociedad-democratica/ Consulta: 
$(12 / 12 / 2018)$

Jardin, André (1989). Historia del liberalismo político. De la crisis del absolutismo a la Constitución de 1875, trad. Francisco González Aramburu FCE, México.

Librería Norma (s/f) Autores: Omar Rincón [En línea] Disponible en: http://www.librerianorma.com/autor/autor.aspx?p=OfUhlBI99BH+k8ExZ$\underline{\mathrm{b} 8+\mathrm{rrNZi}} \mathrm{n}+33 \mathrm{G}+$

Macaroff, A. (2010). “¿Es posible democratizar la comunicación? Debates sobre los medios públicos y privados en el Ecuador". FLACSO Andes. Ágora, espacio de autoarchivo e intercambio de documentos y trabajos de investigación. Quito.

MacBride, S. (1993). Un solo mundo, voces múltiples. Comunicación e información en nuestro tiempo. Ed Fondo de Cultura Económica. México.

Minga, Ana. "Agarra lo que puedas" en los medios públicos. En Revista Plan $V$ http://www.planv.com.ec/ideas/ideas/agarra-lo-que-puedas-medios-publicos. Consultado el 20 de enero de 2019.

Muro Benayas, Ignacio (2006). Globalización de la información y agencias de noticias. Entre el negocio y el interés general. Paidós. Barcelona.

"Medios Públicos: Un derecho". En http://www.eltiempo.com.ec/noticias/columnistas/1/424413/medios-publicos-un-derecho

"Medios en manos del estado desacreditaron a candidato Guillermo Lasso durante cinco horas en primera semana de campaña electoral para 2 da vuelta". Fundamedios. En http://www.fundamedios.org/medios-en-manos-del-estado-desacreditaron-candidato-guillermo-lasso-durante-cinco-horas-en-primera-semana-de-campana-electoral-para-2da-vuelta/ Consulta: $12 / 12 / 2018$

Medios Públicos del Ecuador (2015). "Los medios públicos son fun246 
damentales en el sostenimiento de la democracia" http://anccom.sociales. uba.ar/2016/01/19/los-medios-publicos-son-fundamentales-en-el-sostenimiento-de-la-democracia/Consunta: 12/12/2018

"Medios públicos en el siglo XXI". En Infociudadana http://www.infociudadana.org.ar/general/ciclo-medios-publicos-en-el-siglo-xxi/ Consulta: $12 / 12 / 2018$

Rodríguez, R. (2004). “Teoría de la Agenda-Setting” (pp. 17-21). Observatorio Europeo de Tendencias Sociales. www.obets.ua.es Disponible en: http://www.obets.ua.es/obets/libros/AgendaSetting.pdf

Sádaba, Teresa (2001). “Origen, aplicación y límites de la teoría del encuadre (framing) en Comunicación”. Comunicación y Sociedad. Facultad de Comunicación, Universidad de Navarra. Pamplona, España.

Souza, Boaventura (2010). "Hablemos del Socialismo del Buen Vivir". Extraído de http://www.plataformabuenvivir.com/wp-content/ uploads/2012/07/SouzaSantosSocialismoBuenVivir2010.pdf Consulta: $09 / 01 / 19$

Rincón, Omar (2010). “Por qué nos odian tanto? Estado y medios de comunicación en América Latina”. Extraído de http://library.fes.de/pdf-files/ bueros/c3-comunicacion/07475.pdf Consulta: 12/12/2018

Rincón, Omar (2009). "Los medios públicos, como militantes de un proyecto de sociedad". En http://www.pichinchauniversal.com.ec/los-medios-publicos-como-militantes-de-un-proyecto-de-sociedad/_Consulta: $12 / 12 / 2018$ 